\title{
The Effect of Functionally Graded Materials into the Sandwich Beam Dynamic Performance
}

\author{
Saber A. Rabboh ${ }^{1}$, Nadia E. Bondok ${ }^{2,3}$, Tamer S. Mahmoud ${ }^{1}$, Heba I. El Kholy ${ }^{4}$ \\ ${ }^{1}$ Mechanical Engineering Department, Shoubra Faculty of Engineering, Banha University, Banha, Egypt; ${ }^{2}$ Department of Technol- \\ ogy Development, Specified Studies Academy Worker's University, Cairo, Egypt; ${ }^{3}$ Faculty of Design and Architecture, Jazan Uni- \\ versity, Jazan, KSA; ${ }^{4}$ Faculty of Engineering, Industrial Education, Beni-Suef University, Beni-Suef, Egypt. \\ Email: nanabondok2012@Yahoo.com
}

Received September $4^{\text {th }}$, 2013; revised October $17^{\text {th }}, 2013$; accepted November $5^{\text {th }}, 2013$

Copyright (C) 2013 Saber A. Rabboh et al. This is an open access article distributed under the Creative Commons Attribution License, which permits unrestricted use, distribution, and reproduction in any medium, provided the original work is properly cited.

\begin{abstract}
The original purpose of FGMs was the development of super resistant materials for propulsion systems. In the present work, numerical and experimental techniques are used to investigate the dynamic behavior of generally laminated composited beams. In the numerical analysis, the laminated beam is modeled using the commercial finite element software ANSYS. In the experimental study the core and face materials of sandwich beam specimens are nylon/epoxy FGMs and pure epoxy laminates respectively. The dynamic behavior of the sandwich composite beam specimens with different fiber orientation was carried out using two dynamic excitation techniques, harmonic using harmonic response and impulse using hammer. The specimens were prepared in the following configurations, different orientation angles, different layers, and different thickness. The results reveal that the natural frequencies of sandwich beam were affected directly by the face materials. The natural frequency decreases with increasing fiber orientations of the nylon/epoxy face laminates. Increasing the thickness increases natural frequencies. This study concluded that it is useful for the designers to select the fiber orientation angle to shift the natural frequencies as desired or to control the vibration level.
\end{abstract}

Keywords: Sandwich Beam; FGM; Nylon/Epoxy; Natural Frequency; Fiber Orientation

\section{Introduction}

FGMs are a new generation of engineered materials first introduced by a group of Japanese scientists in 1984. The original purpose of FGMs was the development of super resistant materials for propulsion systems and air frame of the space planes in decreasing thermal stresses and increasing the effect of protection from heat.

The concept of FGMs emerged from the need to fabricate a new composite for high temperature structural applications by using a heat resistant ceramic on the high temperature side and a metal on the low temperature side to provide mechanical toughness. Anisotropy of these composite allows the designer to tailor the material in order to achieve the desired performance requirement, so it is fundamental importance to develop tools that allow the designer to obtain optimized designs considering the structure requirement; and functional characteristics imposed by the production process. In engineering parties it is of vital importance to induct thy dynamic analysis of structures [1], and the dynamic analysis in mechanical design is of great importance to control the vibration in order to maintain the operating performance and to prevent sudden failures in the structures. The occurrence of resonance will decrease the life time of the structure and cause unpredictable failures. A variety of structure components made of FMGs such as turbine blades, aircraft wings and aerospace can be approximated as laminated composite sandwich beams, which require a deeper understanding of the vibration characteristics of the composite sandwich beams [2]. Therefore, it is essential to know characteristics of these structures, which may be subject to dynamic loads in complex environmental conditions. If the frequency the loads variation matches one of resonance frequencies of the structure, large torsion defections and internal stress can occur, which may lead to failure of the structure components. To avoid the typical problems caused by vibrations it is important to determine natural frequencies of the structure and modal shapes to reinforce the most flexible regions, or damping should be increased. 
FGMs composed of two material constituents mixed together with locally prescribed volume fractions have been the focus of the majority of the literature concerning FGMs and will be the focus of the study. Most authors deal with epoxy and nylon. Hajime et al. [3] studied the damping properties of carbon fiber-reinforced interleaved epoxy composites. Several types of thermoplastic-elastomeric films, such as polyurethane elastomers, polyethylene-based ionomers and polyamide elastomers, were used as the interleaving materials. The damping properties of the composite laminates with/without the interleaf films were evaluated by the mechanical impedance method. Also, the effects of the lay-up arrangements of the carbon-fiber prepregs on the damping properties of the interleaved laminates were examined. The stiffness of the films at the resonant frequency of the laminates was another important parameter that controlled the loss factor of the interleaved laminate.

Khondker et al. [4] showed that the presence of fiber/ matrix interfaces strongly influences the overall mechanical properties of composites. Polyamide materials were chosen and combined with Aramid fiber in an attempt to achieve better interfacial bonding. Aramid/epoxy knitted composites were also fabricated to compare them with aramid/nylon thermoplastic composites. Processing time, tensile modulus and strength of Aramid/ nylon composites have increased and decreased, respectively. Aramid/nylon knitted composites have revealed comparable strength property in the course direction, albeit they have inferior tensile strength in the wale direction when compared to that in Aramid/epoxy composites. In Aramid/nylon knitted composites, while tensile modulus exhibited an increasing trend, there were clear drops in tensile strengths with longer molding time. This indicates that there could be an optimum molding condition at which maximum tensile properties can be obtained.

In the work carried out by Meng-Kao et al. [5], the faces of sandwich beams were graphite/epoxy laminates. Epoxy and phenol resins served as a matrix material, and multi-walled carbon annotates (MWNTs) provided reinforcement of the fabricated MWNT/polymer nanocomposites as core materials for sandwich beams. The finite element method was used for free vibration analysis of the sandwich beams; the natural frequencies and mode shapes of the sandwich beams were calculated numerically. The experimental and numerical investigation of the dynamic properties of sandwich beams with MWNT/ polymer nano composites as core materials, concluded that the face laminate dominates the stiffness of the sandwich beams, and that the natural frequencies of sandwich beams were affected directly by the face materials and decreased with increasing fiber orientations of the graphite/epoxy face laminate.
A large number of investigators address the problem of free vibration with free vibration analysis of FGMs. Khalili et al. [6] studied the free vibration of three-layered symmetric sandwich beam which is investigated using dynamic stiffness and finite element methods. To determine the governing equations of motion by the present theory, the core density has been taken into consideration. Natural frequencies and mode shapes are computed by the use of numerical techniques. After validation of the present model, the effect of various parameters such as density, thickness and shear modulus of the core for various boundary conditions on the first natural frequency is studied. The study concluded that the face properties like density, thickness are remained constant, but the core properties are varied. Irrespective of the boundary conditions, increasing the core/face density ratio decreases the first natural frequency of the beam.

Galal et al. [7] studied the free vibration characteristics of laminated composite beams (LCBs) which are one of the bases for designing and modeling of industrial products. In this study, the flexural vibrations of LCBs are analyzed analytically using Bernoulli-Navier hypothesis theory. The commercial finite element program ANSYS 10.0 is used to perform a dynamic modeling to the laminated beams. Mindlin eight-node isoperimetric layered shell elements (Shell 99) are employed in the modeling for describing the bending vibrations of these laminated sandwich beams. The study concluded that out-of plane bending frequencies decrease, in general, as the fiber angle increases, in the case of the effect of fiber orientation.

Simsek et al. [8] investigated the free vibration characteristics and the dynamic behavior of a functionally graded simply supported beam under a concentrated moving harmonic load. Trial functions denoting the transverse and the axial deflections of the beam are expressed in polynomial forms. The constraint conditions of supports are taken into account by using Lagrange multipliers. It is assumed that material properties of the beam vary continuously in the thickness direction according to the power-law form. The study concluded that the effects of the different material distribution, velocity of the moving harmonic load, the excitation frequency on the dynamic responses of the beam are discussed. It is observed from the investigations that the above-mentioned effects play very important role in the dynamic behavior of the FG beam.

Xian-Kun et al. [9] deals with the small- and largeamplitude vibrations of compressively and thermally post-buckled sandwich plates with functionally graded material FGM face sheets in thermal environments. Both heat conduction and temperature-dependent material properties are taken into account and the material properties of both FGM face sheets and a homogeneous sub- 
strate are assumed to be temperature dependent. The results show that, as the volume fraction index increases, the fundamental frequency increases in the pre-buckling region, but decreases in the post-buckling region.

In the work carried out by Mohammed et al. [10,11], a generalized model presenting the sandwich beams was developed to calculate the flexural rigidity and sandwich beams dynamic characteristics. Different cases such as sandwich beams multi-layer cores, sandwich beams multi cells, sandwich beams with holes in its cores having different shapes and different orientations were investigated. The finite element code ANSYS 11 was used for free vibration analysis of the sandwich beams; the natural frequencies, mode shapes, and the static deflection of the sandwich beams were calculated. The study concluded that the finite element code ANSYS 11 was used for free vibration analysis; the natural frequencies, mode shapes, and the static deflection of the sandwich beams are calculated. The investigation revealed that the static and dynamic responses of the sandwich beams can be adjusted to the increasing of the number of cores or the number of cells. Shapes and the static deflection of the sandwich beams were calculated. The obtained results from the finite element code ANSYS 11 such as static deflections, static rigidity and natural frequencies were compared with that obtained from the generalized equations according to the cases of investigations which appear to be in good agreement with each others, therefore the generalized model can be used for the best design of the sandwich beams.

In the present work, a FME model analysis and experimental techniques are used to investigate the dynamic behavior of generally laminated composited sandwich beams, for different cases such as sandwich beams FGM cores with different layers, different angles and different thicknesses by using core and face materials of sandwich beam specimens from Nylon/epoxy FGMs and pure epoxy laminates respectively.

\section{Materials}

\subsection{The Matrix}

Epoxy resin was used as a matrix material. The type of epoxy resin used in the present investigation is KEMAPOXY 150 manufactured by Chemicals for Modern Buildings Company (CMB), Egypt. Epoxy resin is a thermoses' resin with good thermal and environmental stability.

\subsection{Nylon Fiber}

In the present work Nylon fibers were used as reinforcing agent. Nylons are semi-crystalline polymers. The amide group (-CO-NH-) provides hydrogen bonding between polyamide chains, giving nylon high strength at elevated temperatures, toughness at low temperatures, combined with its other properties, such as stiffness, wear and abrasion resistance, low friction coefficient and good chemical resistance.

\section{Mould Preparation}

Two different types of cuboids moulds were used to prepare the FGMs sandwich beams. Each mould consists of four sheets of plastic representing the wall sides. The first mould was used to prepare four layers FGM sandwich beams while the second mould was used to prepare the five layers sandwich beams. The dimension of each mould is $25 \times 100 \times 100 \mathrm{~mm}^{3}$ (height $(\mathrm{h}) \times$ length $(\mathrm{L}) \times$ width (b)) as shown in Figure 1.

The sheets were punched into small holes using CNC machine. Holes has $1 \mathrm{~mm}$ diameter. To change nylon ratio inside the layers, the punches of each row are arranged as shown in Figures 2 and 3.

\section{Specimens Preparation}

The epoxy and hardener were mixed by a mechanical mixer with speed 300 rpm for 3 minutes in a temperature

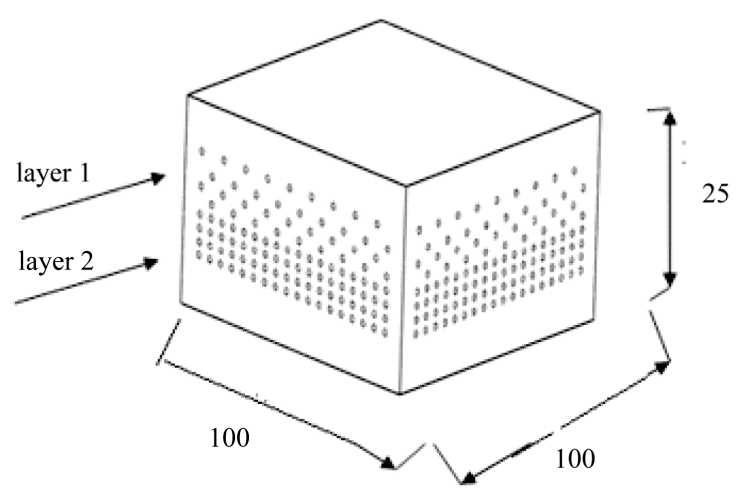

(a)

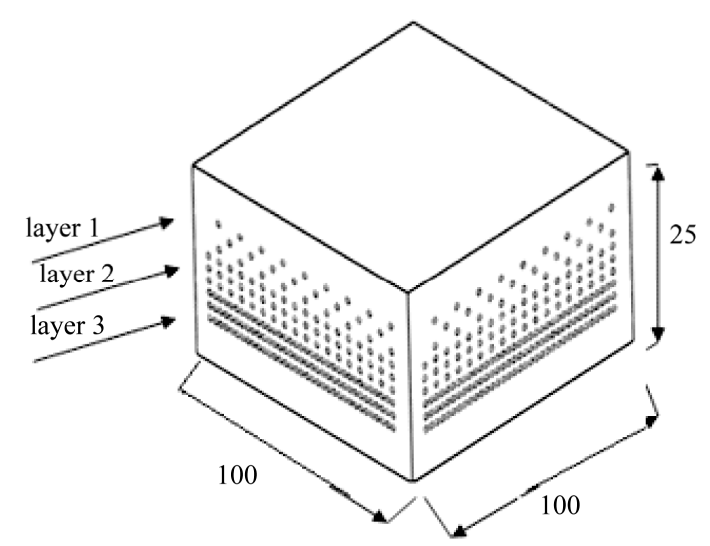

(b)

Figure 1. Moulds used to manufacture FGMs sandwich beam specimens: (a) Four layers mould and (b) Five layers mould. Dimensions in $\mathbf{m m}$. 


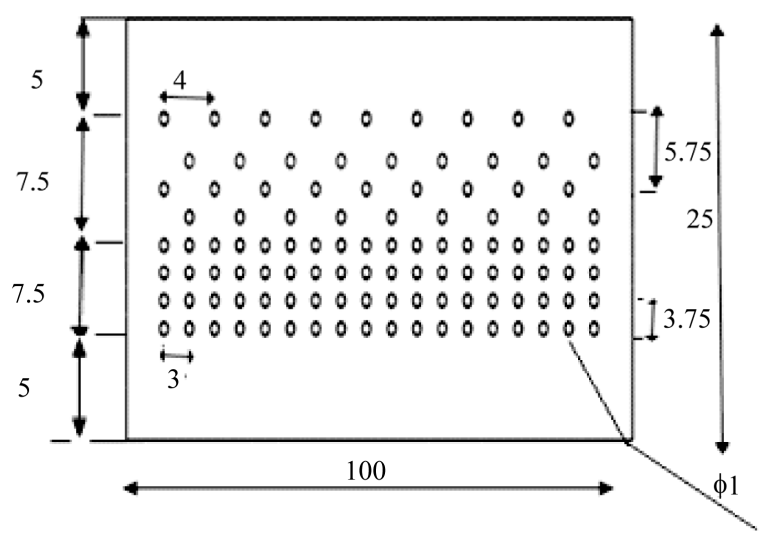

Figure 2. Face of plastic sheet used to fabricate four layers FGM sandwich beams showing two different holes layers. Dimensions in mm.

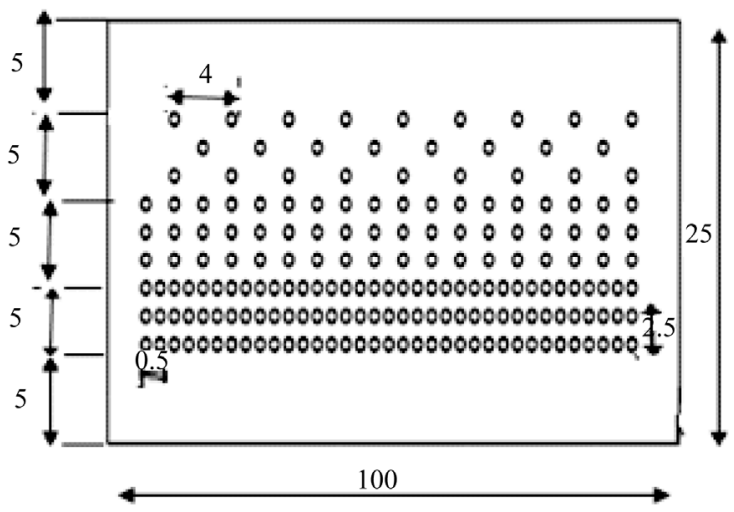

Figure 3. Face of plastic sheet used to fabricate five layers FGM sandwich beams showing three different holes layers. Dimensions in mm.

in room temperature. After that the epoxy/hardner mixture was poured in the plastic mould. The resin-containing nylon-fiber/epoxy was allowed to cure for about a week. After curing, test specimens were cut using an automatic saw with two different thicknesses, typically, $25 \mathrm{~mm} \times 100 \mathrm{~mm} \times 20 \mathrm{~mm}$ and $25 \mathrm{~mm} \times 100 \mathrm{~mm} \times 10$ $\mathrm{mm}$.

Nylon fibers having diameter of $0.5 \mathrm{~mm}$ were woven into the holes of mould faces. Several specimens with different nylon fibers orientations were prepared. Figure 4 show the nylon fibers orientations for the four and five layers specimens. For each layer systems (i.e. four and five layers) the volume fraction of the nylon fibers in each layer varies. Six types of FGM sandwich beam specimens were prepared as shown in Figures 5 and $\mathbf{6 .}$ The total number of specimens was twelve (two specimens each have thickness form each FGM sandwich beam).

Figures 5 and $\mathbf{6}$ also shows the volume fractions of both the epoxy and nylon fibers in the layers of four and five layers specimens, respectively. In these Figures, the

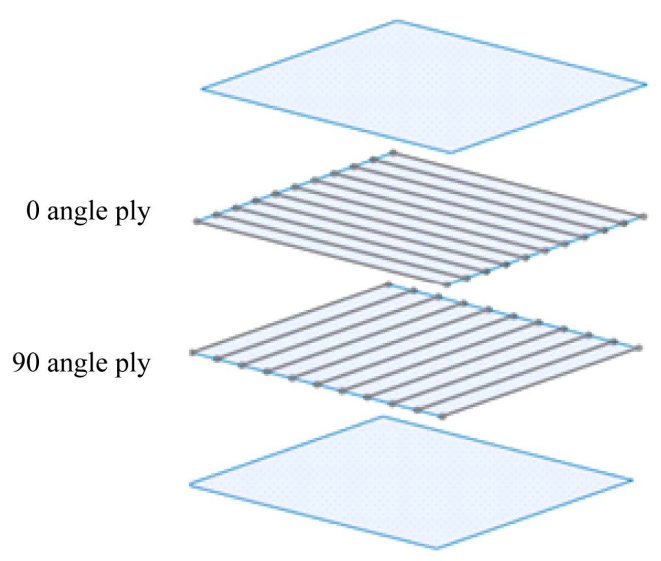

(a)

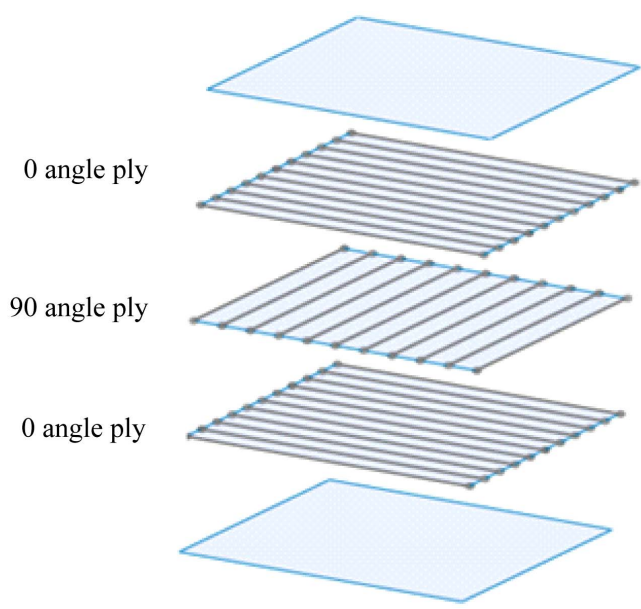

(b)

Figure 4. Schematic illustration of fabricated laminated composites with (a) four layers and fiber orientation (0/90) and (b) five layers and fiber orientation (0/90/0).

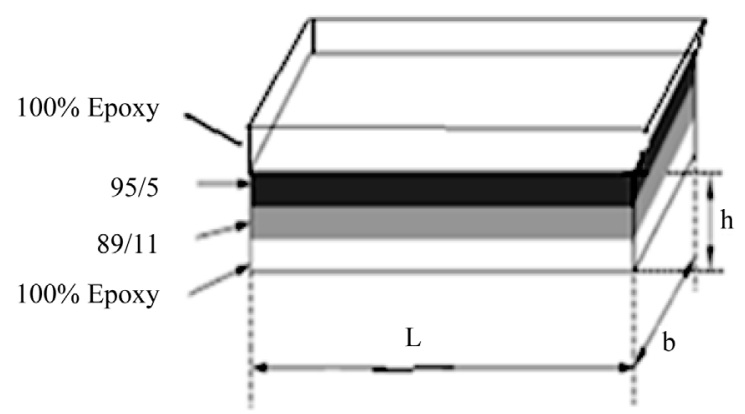

Figure 5. Schematic illustration of sandwich FGM beams having 4-layers showing the volume fraction of epoxy/nylon for specimens with fiber orientation.

layer 96/4 means that the volume fractions of the epoxy matrix and the nylon fibers are $96 \%$ and $4 \%$, respectively.

\section{Material Characterization}

The material elastic properties of the lamina of test spe- 


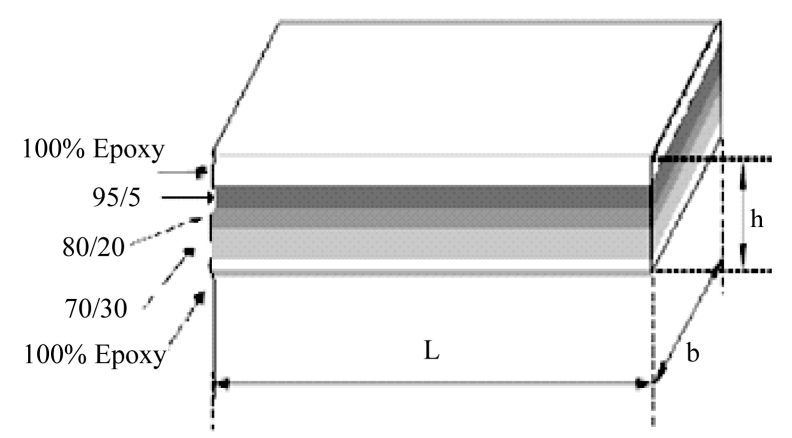

Figure 6. Schematic illustration of sandwich FGM beams having 5-layers showing the volume fraction of epoxy/nylon for specimens with fiber orientation.

cimens are determined through the simple rule of mixtures. These properties are Young's module $\left(E_{1}-\right.$ in direction $1, E_{2}$-in direction 2, $E_{3}$-in direction 3$)$. Passions' ratios $\left(v_{12}, v_{13}, v_{23}\right)$. In plane shear modulus $\left(G_{12}\right)$ and transverse shear modules $\left(G_{13}\right.$ and $\left.G_{23}\right)$ as referred in Figure 7. This figure defines the material principal axes for a typical woven fiber reinforced lamina. Axis 1 is along the fiber length and represents the longitudinal direction of the lamina; axes 2 and 3 represent the transverse in plane and through the thickness directions respectively. The tables in the Appendix indicated the Material properties of core sandwich beam fiber orientation for three angles $(0,45,90)$.

\section{Calculation Percentage of Fiber}

To calculate the ratio of nylon for each layer the area of each hole, and the volume fraction of fiber and matrix are estimated by the following equations

$$
\begin{aligned}
& v_{f}=\frac{V_{f}}{\left(V_{f}+V_{m}\right)} \\
& v_{f}+v_{m}=1
\end{aligned}
$$

where $v_{f}$ and $v_{m}$ are the volume fraction of the fiber, matrix respectively.

By using densities of the fiber $\rho_{f}$, matrix $\rho_{m}$ and composite $\rho_{c}$, respectively, the fiber volume fraction $v_{f}$ can be obtained by Equation (2)

$$
\rho_{c}=\rho_{f} v_{f}+\rho_{m} v_{m}
$$

Using the relation of Equation (3) the fiber volume faction $v_{f}$ is found according to the densities of fiber and matrix present in Table 1 (Appendix). Then, the elastic constants of the woven fabric composite material are numerically estimated using the relation which are based on their constituent properties .the young's modulus and the Poisson ratio of the fill and warp directions are calculated and taken as an average of the longitudinal and transverse values of thee corresponding unidirectional layer.

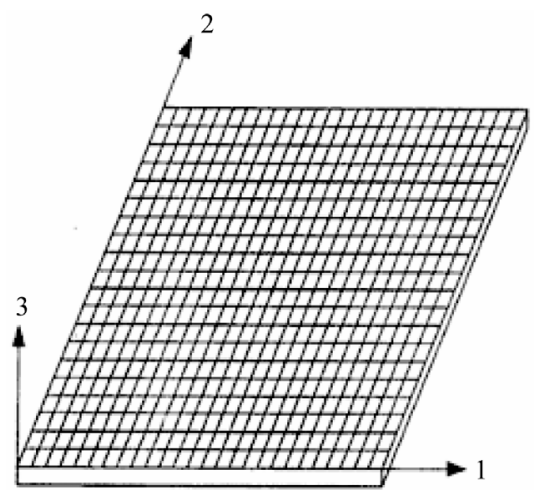

Figure 7. Lamina reference axes.

Table 1. The mechanical properties of constituents of test pecimens, nylon/epoxy.

\begin{tabular}{cccc}
\hline \multirow{2}{*}{ Material } & \multicolumn{3}{c}{ Properties } \\
\cline { 2 - 4 } & $\begin{array}{c}\text { Elasticity modulus } \\
\text { (Gpa) }\end{array}$ & $\begin{array}{c}\text { Density } \\
\left(\mathbf{k g} / \mathbf{m}^{\mathbf{3}}\right)\end{array}$ & Poisson ratio \\
\hline Epoxy resin & 10 & 1800 & 0.4 \\
Nylon fiber & 3 & 1130 & 0.2 \\
\hline
\end{tabular}

The elastic constants and passion ratio of the unidirectional composite are calculated using the simple rule of mixtures by the relations of Equations (1)-(8) [10]

$$
\begin{aligned}
& E_{1}=E_{f} v_{f}+E_{m} v_{m} \\
& E_{2}=E_{m}\left[\frac{E_{f}+E_{m}+\left(E_{f}-E_{m}\right) v_{f}}{E_{f}+E_{m}-\left(E_{f}-E_{m}\right) v_{f}}\right] \\
& v_{23}=v_{f} v_{f}+v_{m}\left(1-v_{f}\right)\left[\frac{1+v_{m}-v_{12} E_{m} / E_{11}}{1+v_{m}^{2}-v_{m} v_{12} E_{m} / E_{11}}\right] \\
& G_{12}=G_{m}\left[\frac{G_{f}+G_{m}+\left(G_{f}-G_{m}\right) v_{f}}{G_{f}+G_{m}-\left(G_{f}-G_{m}\right) v_{f}}\right] \\
& G_{23}=\frac{E_{22}}{2\left(1+v_{23}\right)} \\
& v_{12}=v_{f} v_{f}+v_{m}\left(1-v_{f}\right)
\end{aligned}
$$

where indices $m$ and $f$ denote matrix and fiber, respectively.

\section{Experimential Dynamictesting Methods}

\subsection{Impulse Excitation Technique}

The natural frequencies of the free vibration modes where measured for boundary conditions, cantilever using the impact-testing method. The experimental setup is schematically shown in Figure 8. The impulse was provided with Bruel \& Kjaer (B\&K) made impulse excitation technique hammer of Type 8207 with steel tip hav- 


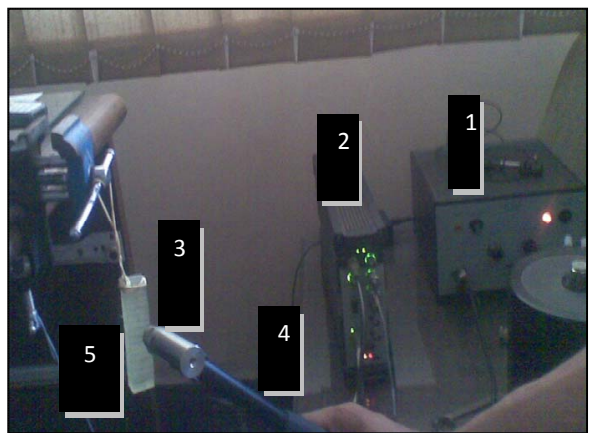

Figure 8. Impulse excitation technique apparatus. 1-power amplifier-type 2706; 2-B \& K portable PULSE 3560B (analyzer); 3-heavy duty impulse excitation technique hammers-types 8207; $4-4507$ piezoelectric IEPE accelerometers; 5-specimen.

ing impulse excitation technique duration of 0.25 - $2 \mathrm{~ms}$ and maximum frequency of $25 \mathrm{kHz}$. The response was measured with B\&K 4507 accelerometer having a weight of $3 \mathrm{~g}$, fixed on the beam surface with adhesive wax. The signal from the accelerometer was fed into a five channel Fast Fourier Transform (FFT) analyzer (B\&K Pulse Analyzer 3560B) via a charge amplifier (B\&K 2706). The FFT of the time domain response from the accelerometer was computed using the software Pulse computer, version 6.0, to obtain the frequency response function (FRF), whose peak locations give the natural frequencies of various modes. The frequencies to $12 \mathrm{kHz}$ were measured for all samples. To ensure that the accelerometer signal is captured from the start of the impulse, the analyzer was set to a pre-trigger delay, so that it starts sampling before the impulse excitation technique occurs. Figure 9 shows the frequency response of a typical sandwich beam.

\subsection{Harmonic Response Technique}

The natural frequencies of the free vibration modes were measured for boundary conditions, cantilever using the harmonic response method. The experimental setup is schematically shown in Figure 10. The impulse was provided with vibration Exciter-Type 4809 with robust titanium housing with integrated titanium connector. The response was measured with B\&K 4507 accelerometer according to the previous conditions which using with impulse excitation technique testing method. Figure 11 shows the frequency response of a typical sandwich beam.

\section{Dynamic Modeling by the Finite Element}

The beams were discretized using finite element (shell99) as, this element has 8 nodes and is available in the commercial package ANSYS. It is constituted by layers that are designated by LN-Layer Numbers which, increasing from the bottom to the top of the laminates; the last number quantifies the existent total number of layers in the laminates (NL-Total Number of Layers). The element has six degrees of freedom at each node: translations in the nodal $\mathrm{x}, \mathrm{y}$, and $\mathrm{z}$ directions and rotations about the nodal $\mathrm{x}, \mathrm{y}$, and $\mathrm{z}$-axes. The choice of shell99 element type is based on layered applications of a structural shell model, and the type of results that need to be calculated.

Modal analysis will be carried out with ANSYS 11.0 finite element software. A modal analysis typically is used to determine the vibration characteristics (natural frequencies and mode shapes) of a structure in the design stages. It can also serve as a starting point for another, more detailed, dynamic analysis, such as a harmonic response, or a spectrum analysis.

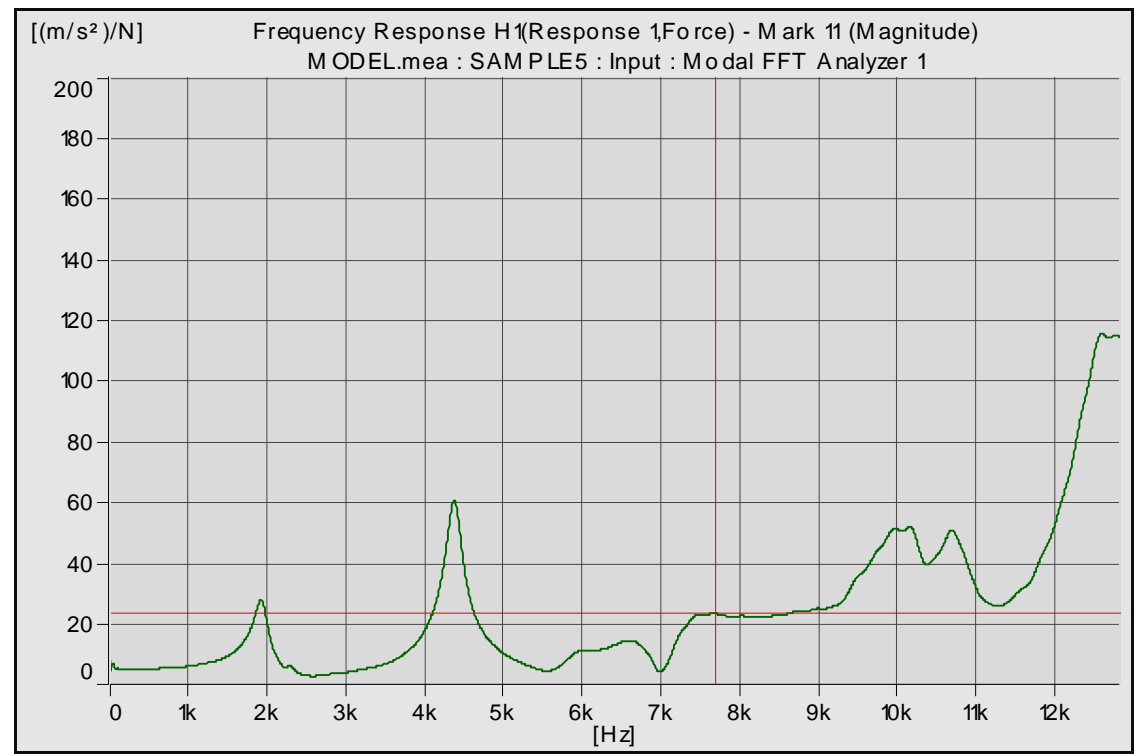

Figure 9. Frequency response of a typical sandwich beam. 


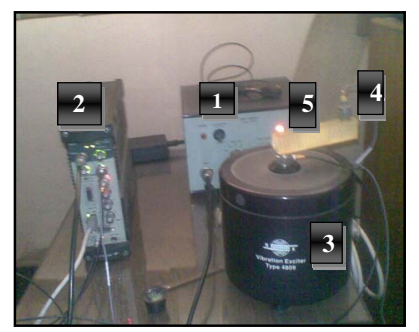

Figure 10. Harmonic response testing equipment. 1-power amplifier-type 2706; 2-portable PULSE 3560B (analyzer); 3-vibration exciter-type 4809; 4-specimen; 5-4507 piezoelectric IEPE accelerometers.

\section{Finite Element Modeling}

The finite element code ANSYS 11 was used for free vibration analysis of the sandwich beams; the natural frequencies and mode shapes and the static deflection of the sandwich beams were calculated. Element shell99 having eight nodes and six degrees of freedom per node, was used. The obtained results such as natural frequencies were compared with the sandwich beam are made face of isotropic materials and core of many plies of orthotropic materials as shown in Figure 12. In the analysis the material properties of the core and face materials of sandwich beams indicate to (Appendix (a)) the sandwich beam width $=100 \mathrm{~mm}$, length $\mathrm{L}=100 \mathrm{~mm}$ and thickness $b=20$. A perfect bonding at the interface between the face and the core materials was assumed. The sandwich beam is considered to be cantilever type, i.e. fixed at one end.

\section{Result and Discussion}

Table 2 show the comparison between the experimental and FE mode results for the impulse excitation technique damped natural frequencies obtained by free vibration test for all types of laminated sandwich beam previously mentioned also Figure 13 indicated this comparison of the natural frequencies, equivalent to the damping characteristics for the laminated sandwich beam with thickness $20 \mathrm{~mm}$ of fiber angle $0^{\circ}, 45^{\circ}, 90^{\circ}$.

\subsection{Influence of Number of Layer on Vibration of Sandwich Beam}

The influence of increase the number of layers and amount of fiber for the same total thickness of the free vibration for the laminated sandwich beam is investigated. The analysis is preformed using experimental test and finite element method. The results indicated that increase the number of layer increase natural frequencies of the sandwich beam as shown in Figure 13.

Variation of flexural frequencies with respect to fiber angle change of woven roving laminated beams are presented in Figure 13. The experimental frequencies are plotted with the ANSYS results against fiber angle of woven roving laminated beams.

This is due to possibility is present in symmetric angle ply laminated and the regularity of the distribution of the proportion of the different fiber in each layer .This is possibility makes one or more of these materials very attractive since due possibility is present in symmetric it makes possibility to obtain the desired natural frequencies without increasing mass or changing geometry. In practical application, it means that if a natural frequency excites the structure, the designer changes the material properties by changing parentage of fiber in each layer, changing geometry.

\subsection{The Influences of Fiber Orientation Are Investigated}

The material properties of the core laminate of sandwich beams were varied through the fiber orientations in core

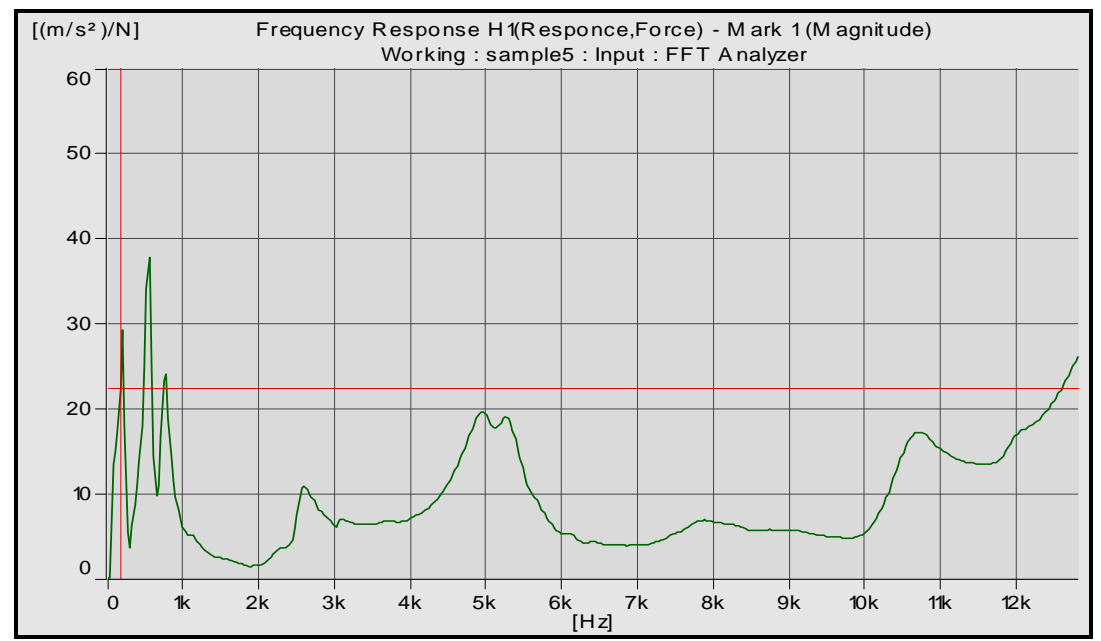

Figure 11. Frequency response of a typical sandwich beam. 


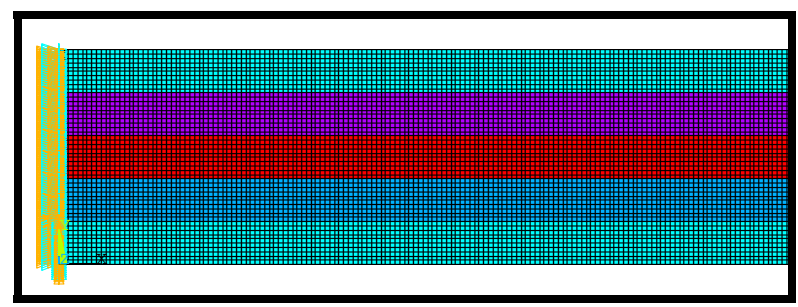

Figure 12. Sketch of five layers symmetric of sandwich beam.

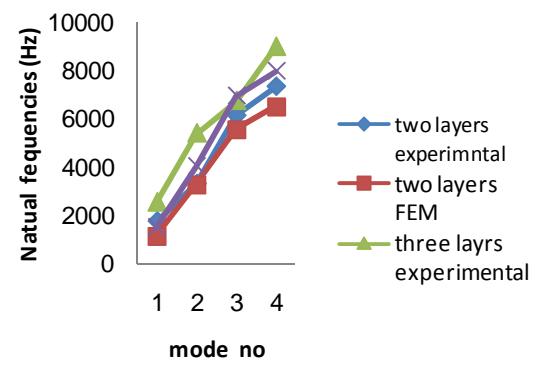

(a)

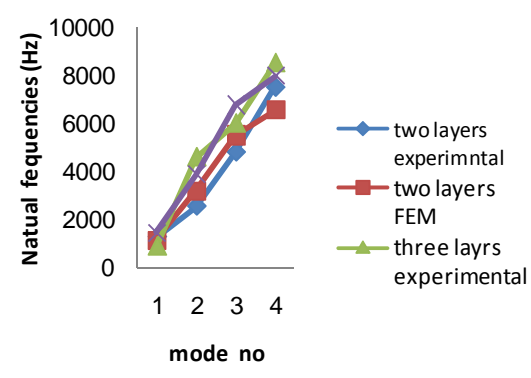

(b)

Figure 13. Experimental test and theoretical variation natural frequencies, of four layers and to five layers versus, mode of variation using (impulse). (a) At fiber orientation $\theta$ $=0^{\circ}$ and (b) At fiber orientation $\theta=90^{\circ}$.

nylon/epoxy laminates. Figure 14 shows the natural frequencies of the bending modes of sandwich beams with an epoxy face and varied fiber orientation in the nylon/epoxy core laminate; the fiber orientations in nylon/epoxy core laminates are fabricated with angles (0/90), (45/90) and (90/-90). According to Figure 14, the natural frequencies of the sandwich beams decrease with increasing fiber orientation of the core laminate.

From these results, it is possible to verify the influence of fiber orientation on the free flexural vibration of laminated beams. It is found that the maximum flexural frequency occurs at $\theta=0^{\circ}$ and the minimum occurs at $90^{\circ}$. This can be explained by the fact that the fibers oriented at $0^{\circ}$ are more appropriate to flexural loads.

Variation of flexural frequencies with respect to fiber angle change of woven roving laminated beams are presented in Figure 14. The experimental frequencies are plotted with the ANSYS results against fiber angle of woven roving laminated beams.
Table 2. Comparison of natural frequencies $(\mathrm{Hz})$ between ANSYS and experimental (impulse excitation technique, harmonic response technique) for woven FGM laminated sandwich beams.

\begin{tabular}{cccccc}
\hline \multicolumn{5}{c}{ ORINTATION (20) impulse excitation technique } \\
\hline exp & ANSYS & exp & ANSYS & exp & ANSYS \\
\hline 90 & 90 & 45 & 45 & 0 & 0 \\
880 & 1470 & 2448 & 1460 & 2528 & 1504 \\
4600 & 3881 & 5120 & 3921 & 5400 & 4001 \\
6000 & 6762 & 7024 & 6858 & 6744 & 6960 \\
8520 & 7969 & 9016 & 7719 & 8992 & 7957 \\
9328 & 11475 & 11860 & 11876 & 13000 & 12123 \\
& ORINTATION (20) harmonic response technique & \\
exp & ANSYS & exp & ANSYS & exp & ANSYS \\
90 & 90 & 45 & 45 & 0 & 0 \\
160 & 609 & 544 & 559 & 544 & 609 \\
736 & 1209 & 800 & 1659 & 800 & 1209 \\
4544 & 4806 & 5344 & 4406 & 5728 & 4806 \\
7360 & 9602 & 8928 & 8802 & 9536 & 9602 \\
9512 & 1200 & 11490 & 10450 & 12480 & 1200 \\
\hline & & & & &
\end{tabular}

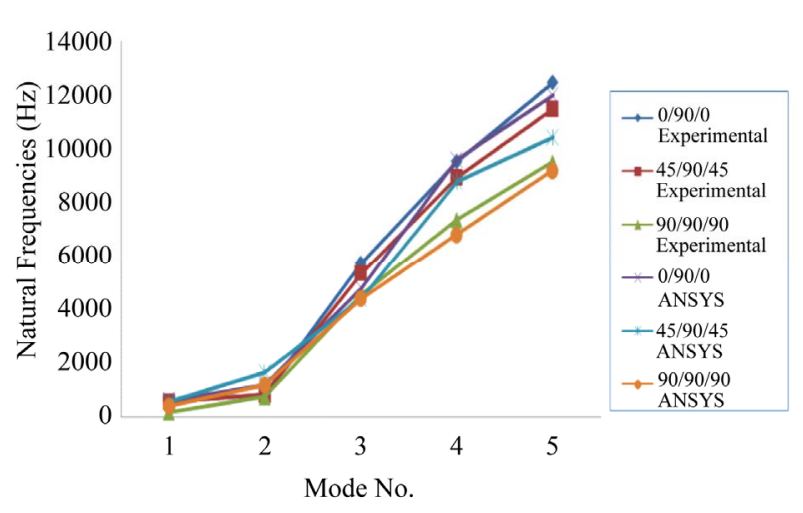

Figure 14. Natural frequencies of sandwich beam from FE model and Harmonic response method for five layers.

With relation to the deviations of the FE modal results in relation to the experimental ones, come possible measurement errors can be pointed out such as: measurement noise, positioning of the accelerometers and their mass, non-uniformity in the specimens properties (voids, variations in thickness, non uniform surface finishing). Such factors are not taken into account during the numerical analysis, since the model considers the specimen entirely perfect and with homogeneous properties, what rarely occurs in practice. Another aspect to be considered is that the input properties in the model came from the application of the rule-of mixtures and they do not take into account effects of the fiber-matrix interface as well as the irregular distribution of resin on the fibers. Also, these models did not include damping effects, which can have a large influence on the structure behavior. Also, the 
computational package ANSYS does not allow for the consideration of the fibers interweaving present in the fabric used.

\section{Conclusions}

In this work, the dynamic characteristics of generally laminated FGM composites sandwich beam with different fiber orientations were tested experimentally and theoretically. The main conclusions that can be drawn from this investigation are:

1) The changes in fiber angle yield to different dynamic behaviors of the component, which has, different natural frequencies for the same geometry, mass and boundary conditions, as the fiber angle increases, and the flexural natural frequencies damp, with range $48 \%$ to $8 \%$ related to the change of fiber angle $\left(0^{\circ}\right.$ to $\left.90^{\circ}\right)$ of improve fiber orientation of the epoxy/nylon core FGM laminate.

2) Increasing the thickness leads to the improvement of natural frequencies according to the moment of interia of the sandwich beam cross section.

3) Increasing the number of the layers leads to the improvement of the natural frequencies with range $9 \%$ to $44 \%$ related to the change of fiber angle $\left(0^{\circ}\right.$ to $\left.90^{\circ}\right)$.

\section{REFERENCES}

[1] L. Qi, V. P. Iu and K. P. Kou, "Three-Dimensional Vibration Analysis of Functionally Graded Rectangular Plates,” Journal of Sound and Vibration, Vol. 311, 2006, pp. 362-381.

[2] M. Koizumi, “Concept of FGM," Ceramic Transactions, Vol. 34, 1993, pp. 3-10.

[3] K. Hajime and K. Manabu, "Damping Properties of Thermoplastic-Elastomeric Interleaved Carbon Fiber-Rein- forced Epoxy Composites,” Composites Science and Technology, Vol. 64, No. 16, 2004, pp. 2517-2523. http://dx.doi.org/10.1016/j.compscitech.2004.05.006

[4] T. Khondker, M. Fukui, A. Inoda and H. Nakai, "Fabrication and Mechanical Properties of Aramid/Nylon Plain Knitted Composites," Composites: Part A, Vol. 35, No. 10, 2004, pp. 1195-1205. http://dx.doi.org/10.1016/j.compositesa.2004.03.004

[5] Y. Meng-Kao and H. Tsung-Han, "Dynamic Properties of Sandwich Beams with MWNT/Polymer Nanocomposites as Core Materials," Composites Science and Technology, Vol. 68, No. 14, 2008, pp. 2930-2936. http://dx.doi.org/10.1016/j.compscitech.2007.10.010

[6] S. M. R. Khalili, N. Nemati, K. Malekzadeh and A. R. Damanpack, "Free Vibration Analysis of Sandwich Beams Using Improved Dynamic Stiffness Method”, Composite Structures, Vol. 92, No. 2, 2010, pp. 387-394. http://dx.doi.org/10.1016/j.compstruct.2009.08.020

[7] A. Galal and F. Mohammed, "Effects of Orientation and Laminate Stacking Sequence on Out-of-Plane and InPlane Bending Natural Frequencies of Laminated Composite Beams,” Composite Structures, Vol. 82, 2009, pp. 146-156.

[8] M. Simsek and T. Kocaturk, "Free Vibration Analysis of Beams by Using a Third-Order Shear Deformation Theory,” Vol. 32, 2007, pp. 167-179.

[9] X. Xian-Kun and S. Hui-Shen, "Vibration of Post-Buckled Sandwich Plates with FGM Face Sheets in a Thermal Environment," Journal of Sound and Vibration, Vol. 314, No. 1-2, 2008, pp. 254-274. http://dx.doi.org/10.1016/j.jsv.2008.01.019

[10] M. A. Salam and N. E.Bondok, "Free Vibration Characteristic for Different Configurations of Sandwich Beams," Journal of Sound and Vibration, Vol. 10, 2009, pp. 1-14.

[11] M. A. Salam and N. E.Bondok, "Free Vibration Characteristics for Different Configurations of Sandwich Beams," International Journal of Mechanical \& Mechatronics, Vol. 10, 2010, pp. 41-54. 
Appendix. Material properties of three core layers sandwich beam. (a) Fiber orientation (0/90/0); (b) Fiber orientation (45/90/45); (c) Fiber orientation (90/90/90).

(a)

\begin{tabular}{|c|c|c|c|c|c|}
\hline Properties & Symbol & Unit & Layer 1 & Layer 2 & Layer 3 \\
\hline Fiber volume fraction & $V_{\mathrm{f}}$ & Vol\% & $3 \%$ & $10 \%$ & $15 \%$ \\
\hline Lamina longitudinal modulus & $E_{1}$ & $\mathrm{GPa}$ & 9.8 & 9.3 & 8.95 \\
\hline Lamina transverse elastic modulus & $E_{2}$ & GPa & 9.35 & 8.1 & 7.4 \\
\hline Lamina transverse elastic modulus & $E_{3}$ & GPa & 9.35 & 8.1 & 7.4 \\
\hline Lamina major Poisson’s ratio & $v_{12}$ & & 0.39 & 0.38 & 0.37 \\
\hline Lamina major Poisson’s ratio in plane & $v_{13}$ & & 0.39 & 0.38 & 0.37 \\
\hline Lamina major Poisson’s ratio in plane & $v_{23}$ & & 0.37 & 0.36 & 0.37 \\
\hline Shear modulus in plane & $G_{12}$ & GPa & 3.35 & 3.176 & 2.692 \\
\hline Shear modulus in plane & $G_{13}$ & GPa & 3.35 & 3.176 & 2.692 \\
\hline Shear modulus in plane & $G_{23}$ & GPa & 3.35 & 3.176 & 2.692 \\
\hline Density of composite & $\rho_{\mathrm{c}}$ & $\mathrm{Kg} / \mathrm{m}^{3}$ & 1392 & 1384 & 1360 \\
\hline
\end{tabular}

(b)

\begin{tabular}{|c|c|c|c|c|c|}
\hline Properties & Symbol & Unit & Layer 1 & Layer 2 & Layer 3 \\
\hline Fiber volume fraction & $V_{\mathrm{f}}$ & Vol\% & $4 \%$ & $16 \%$ & $22 \%$ \\
\hline Lamina longitudinal modulus & $E_{1}$ & GPa & 9.7 & 8.88 & 8.46 \\
\hline Lamina transverse elastic modulus & $E_{2}$ & GPa & 9.12 & 7.28 & 6.6 \\
\hline Lamina transverse elastic modulus & $E_{3}$ & GPa & 9.12 & 7.28 & 6.6 \\
\hline Lamina major Poisson’s ratio & $v_{12}$ & & 0.39 & 0.368 & .356 \\
\hline Lamina major Poisson's ratio in plane & $v_{13}$ & & 0.39 & 0.368 & .356 \\
\hline Lamina major Poisson's ratio in plane & $v_{23}$ & & 0.37 & 0.368 & .356 \\
\hline Shear modulus in plane & $G_{12}$ & GPa & 3.28 & 2.65 & 2.4 \\
\hline Shear modulus in plane & $G_{13}$ & GPa & 3.28 & 2.65 & 2.4 \\
\hline Shear modulus in plane & $G_{23}$ & GPa & 3.28 & 2.65 & 2.4 \\
\hline Density of composite & $\rho_{\mathrm{c}}$ & $\mathrm{Kg} / \mathrm{m}^{3}$ & 1389 & 1357 & 1341 \\
\hline
\end{tabular}

(c)

\begin{tabular}{|c|c|c|c|c|c|}
\hline Properties & Symbol & Unit & Layer 1 & Layer 2 & Layer 3 \\
\hline Fiber volume fraction & $\mathrm{V}_{\mathrm{f}}$ & Vol\% & $5 \%$ & $20 \%$ & $30 \%$ \\
\hline Lamina longitudinal modulus & $E_{1}$ & GPa & 9.65 & 8.6 & 7.9 \\
\hline Lamina transverse elastic modulus & $E_{2}$ & GPa & 9.0 & 6.82 & 5.88 \\
\hline Lamina transverse elastic modulus & $E_{3}$ & GPa & 9.0 & 6.82 & 5.88 \\
\hline Lamina major Poisson's ratio & $v_{12}$ & & 0.39 & 0.36 & 0.34 \\
\hline Lamina major Poisson's ratio in plane & $v_{13}$ & & 0.39 & 0.36 & 0.34 \\
\hline Lamina major Poisson's ratio in plane & $v_{23}$ & & 0.36 & 0.36 & 0.34 \\
\hline Shear modulus in plane & $G_{12}$ & GPa & 3.28 & 2.49 & 2.16 \\
\hline Shear modulus in plane & $G_{13}$ & GPa & 3.28 & 2.49 & 2.16 \\
\hline Shear modulus in plane & $G_{23}$ & $\mathrm{GPa}$ & 3.28 & 2.49 & 2.16 \\
\hline Density of composite & $\rho_{\mathrm{c}}$ & $\mathrm{Kg} / \mathrm{m}^{3}$ & 1388 & 1346 & 1319 \\
\hline
\end{tabular}

